\title{
RECENT UPDATES TO NRC FUEL PERFORMANCE CODES AND PLANS FOR FUTURE IMPROVEMENTS
}

\author{
KENNETH GEELHOOD* \\ Pacific Northwest National Laboratory \\ 902 Battelle Blvd. P.O. Box 999 Richland, WA 99352, USA \\ ${ }^{*}$ Corresponding author. E-mail : kenneth.geelhood @ pnnl.gov
}

Received November 01, 2011

FRAPCON-3.4a and FRAPTRAN 1.4 are the most recent versions of the U.S. Nuclear Regulatory Commission (NRC) steady-state and transient fuel performance codes, respectively. These codes have been assessed against separate effects data and integral assessment data and have been determined to provide a best estimate calculation of fuel performance. Recent updates included in FRAPCON-3.4a include updated material properties models, models for new fuel and cladding types, cladding finite element analysis capability, and capability to perform uncertainty analyses and calculate upper tolerance limits for important outputs. Recent updates included in FRAPTRAN 1.4 include: material properties models that are consistent with FRAPCON-3.4a, cladding failure models that are applicable for loss-of coolant-accident and reactivity initiated accident modeling, and updated heat transfer models. This paper briefly describes these code updates and data assessments, highlighting the particularly important improvements and data assessments. This paper also discusses areas of improvements that will be addressed in upcoming code versions.

KEYWORDS : FRAPCON, FRAPTRAN, Fuel Performance, Fission Gas Release, Loss-of-coolant Accident, Reactivity Initiated Accident

\section{INTRODUCTION}

The ability to accurately calculate the performance of light-water reactor (LWR) fuel rods under long-term burnup conditions and various operational transients and hypothetical accidents is a major objective of the reactor safety research program being conducted by the U.S. Nuclear Regulatory Commission (NRC). To achieve this objective, the NRC has sponsored an extensive program of analytical computer code development, as well as both in-pile and out-of-pile experiments to benchmark and assess the analytical code capabilities. The computer code developed to calculate the long-term burnup response of a single fuel rod is FRAPCON-3 under steady-state operation with power changes greater than a few minutes. The computer code developed to calculate the response of a single fuel rod to operational transients and hypothetical accidents is FRAPTRAN. The ongoing development of these two computer codes has been performed for NRC under contract at Pacific Northwest National Laboratory (PNNL) for the past 15 years.

The NRC uses these codes primarily in their review of fuel performance codes and fuel design changes that are submitted for licensing analyses by fuel vendors. The models in FRAPCON-3 and FRAPTRAN and the data used to develop these models are compared to those in the vendor fuel performance code under review or to vendor analyses of new fuel designs. Sample cases performed with the fuel performance code under review are compared to sample cases performed with FRAPCON-3 or FRAPTRAN to identify areas where their predictions are different. If significant differences are found, more data may be provided by the applicant to justify these differences, the difference may be judged to be conservative for safety analyses, or the NRC may apply a penalty to the fuel performance code under review. Because of this use of the NRC fuel performance codes, it is important for the code to provide best-estimate results and to constantly be reassessed against new data and be updated to reflect the use of new fuel or cladding materials.

Briefly described in this paper are the current versions of FRAPCON-3 and FRAPTRAN, recent updates and assessments made on FRAPCON-3 and FRAPTRAN, and future plans for code development. The reader is referred to the reference documents for more details about the model and code updates and the assessment results. 


\section{CURRENT VERSIONS OF FRAPCON-3 AND FRAPTRAN}

The current versions of FRAPCON-3 and FRAPTRAN are FRAPCON-3.4a[1] and FRAPTRAN 1.4[2]. FRAPCON3.4a was released shortly after FRAPCON-3.4 to fix a small error in the corrosion model. The release document matches the coding in FRAPCON-3.4a. These versions are fully described in their associated release documents. In addition, FRAPCON-3.4a and FRAPTRAN 1.4 share a common material properties library for fuel properties, cladding properties, and gas properties. These properties are described in a material properties document [3].

\section{RECENT UPDATES TO FRAPCON-3.4A}

Several significant changes were made in FRAPCON3.4a to improve its predictive abilities relative to FRAPCON3.3. These changes are briefly described in this section and are described in more detail elsewhere [4], and in the FRAPCON-3.4a description document [1]. These changes are divided into three categories; model updates, new modeling capabilities, and methodology updates.

\subsection{Model Updates}

Several material property updates were made to the material property models in areas where new data and data at higher temperatures indicated that the original model did not provide adequate predictions. Recent model to data comparisons demonstrated that the fuel thermal expansion model in FRAPCON-3.3 slightly underpredicted thermal expansion data for temperatures above $2500 \mathrm{~K}$. The model was updated to better fit the available data. The fuel solid swelling rate in FRAPCON-3.3 was compared to swelling rate data from numerous tests performed in Halden [5]. In FRAPCON-3.3, the fuel swelling rate was $0.77 \% \Delta \mathrm{V} / \mathrm{V}$ per $10 \mathrm{GWd} / \mathrm{MTU}$. The observed swelling rate from the more recent Halden data was found to be lower than this below $80 \mathrm{GWd} / \mathrm{MTU}$ and greater than this above 80 $\mathrm{GWd} / \mathrm{MTU}$. The swelling model in FRAPCON-3.4a was changed to use a rate of $0.62 \% \Delta \mathrm{V} / \mathrm{V}$ per $10 \mathrm{GWd} / \mathrm{MTU}$ below $80 \mathrm{GWd} / \mathrm{MTU}$ and $0.86 \% \Delta \mathrm{V} / \mathrm{V}$ per $10 \mathrm{GWd} / \mathrm{MTU}$ above $80 \mathrm{GWd} / \mathrm{MTU}$. The standard error of this model compared to the data is $0.08 \% \Delta \mathrm{V} / \mathrm{V}$ per $10 \mathrm{GWd} / \mathrm{MTU}$ below $80 \mathrm{GWd} / \mathrm{MTU}$ and $0.16 \% \Delta \mathrm{V} / \mathrm{V}$ per $10 \mathrm{GWd} / \mathrm{MTU}$ above $80 \mathrm{GWd} / \mathrm{MTU}$. The reduced swelling rate at low burnup will delay the gap closure prediction in FRAPCON3.4a. The gas conductivity models in FRAPCON-3.3 were compared to data and were found to underpredict gas conductivity at high temperature. The coefficients for each gas were updated in FRAPCON-3.4a to provide a better fit to the data.

Several advanced cladding alloys such as M5 ${ }^{\mathrm{TM}}$, ZIRLO $^{\text {TM }}$, and Optimized ZIRLO ${ }^{\text {TM }}$ are now being used in the U.S. These alloys were not yet developed when the cladding material property correlations in FRAPCON-3 were developed. Although these advanced cladding alloys behave similarly to Zircaloy- 4 and Zircaloy-2, there are some changes that have been accounted for in FRAPCON3.4a. First a model described by Limbäck and Andersson [6] was selected for predicting cladding irradiation creep in FRAPCON-3.4a. This model uses a thermal creep model described by Matsuo [7] and an empirical irradiation creep rate with tuned model parameters that were fit to the data set given by Franklin et al.[8]. The Limbäck and Andersson model was modified by PNNL to use effective stress rather than hoop stress as an input so that the observed difference in creep behavior during outward (tensile) and inward (compressive) creep as a function of hoop stress would be modeled correctly. Using effective stress in the creep rate model provides a better prediction of outward (tensile) and inward (compressive) creep than using hoop stress, e.g. using the same effective stress results in the same creep rate for outward or inward creep. Several of the fitting coefficients were then changed to allow the model to predict data from Zircaloy-2 (recrystallized annealed (RXA)), Zircaloy-4 (stress relief annealed (SRA)), ZIRLOTM (SRA), and M5 ${ }^{\mathrm{TM}}$ (RXA). Optimized ZIRLO ${ }^{\mathrm{TM}}$ (partially recrystallized annealed (PRXA)) is assumed to have the same creep behavior as ZIRLO ${ }^{\text {TM }}$. Second, the cladding axial irradiation growth model in FRAPCON-3.3 applies only SRA Zircaloy-4 and RXA Zircaloy-2. New coefficients have been developed for axial growth in M5 ${ }^{\mathrm{TM}}$ and ZIRLO ${ }^{\mathrm{TM}}$. Third, the cladding corrosion and hydrogen pickup models for Zircaloy-2, Zircaloy-4, ZIRLO ${ }^{\text {TM }}$ and M5 ${ }^{\mathrm{TM}}$ have been compared to recent data and updated in FRAPCON-3.4a as necessary. FRAPCON-3.4a uses a cladding corrosion model with a cubic rate law to model corrosion up to the transition thickness of $2 \mu \mathrm{m}$. After transition, a neutron flux dependent linear rate law is used. The fitting parameters have been selected to accurately model observed corrosion behavior for each of the different cladding alloys. FRAPCON-3.4a uses a burnup dependent hydrogen pickup model for BWR conditions, and a constant hydrogen pickup fraction for PWR alloys. The pickup fraction is different for each PWR cladding alloy.

FRAPCON-3 uses the TUBRNP [9] model to predict the radial power profiles within the fuel pellet as a function of uranium and plutonium isotopic concentration and burnup. This model has been updated in FRAPCON-3.4a to model heavy water reactor HWR conditions as recommended by the original authors of the model[10]. The predictions of this update were verified with neutronic calculations using WIMS[11]. This modification was necessary to accurately model fuel rods in the Halden Boiling Water Reactor (HBWR) because the neutron spectrum in a HWR has relatively more neutrons in the thermal region and relatively fewer neutrons in the fast region compared to a LWR spectrum. Therefore the spectrum-averaged fission and capture cross sections will be different for 
LWR and HWR conditions and the radial power profile will be different. This code update provides slightly improved temperature predictions ( $\sim 20 \mathrm{~K}$ closer to the data on average through life) for $\mathrm{UO}_{2}$ and mixed oxide (MOX) tests performed in the HBWR reactor.

Radial power profiles for $\mathrm{UO}_{2}-\mathrm{Gd}_{2} \mathrm{O}_{3}$ were calculated using the WIMS code [11] for $\mathrm{UO}_{2}-\mathrm{Gd}_{2} \mathrm{O}_{3}$ fuel in LWR and HWR conditions at various $\mathrm{Gd}_{2} \mathrm{O}_{3}$ concentrations. The results of these calculations were put into FRAPCON-3.4a as a data table with a lookup and interpolation routine used to calculate the radial power profile. This routine is used to calculate the radial power profile for $\mathrm{UO}_{2}-\mathrm{Gd}_{2} \mathrm{O}_{3}$ up to a burnup of $7 \mathrm{GWd}$ /MTU. After this burnup, all the ${ }^{155} \mathrm{Gd}$ and ${ }^{157} \mathrm{Gd}$ have burnt out and the $\mathrm{UO}_{2}$ radial power profile model is used for continuing burnup. This code update provides slightly improved temperature predictions (previously underpredicted data early in life when Gd was burning out by $\sim 50 \mathrm{~K}$ ) for $\mathrm{UO}_{2}-\mathrm{Gd}_{2} \mathrm{O}_{3}$ fuel for the period of time while the Gd is burning out.

Two changes were made to the helium $(\mathrm{He})$ production models to improve rod internal pressure calculations. More $\mathrm{He}$ is produced in MOX fuel than in $\mathrm{UO}_{2}$ due to the increased alpha decay in plutonium. He production rates for MOX fuel containing reactor grade plutonium and weapons grade plutonium differ because of isotopic ratios and were provided using the ORIGEN-ARP and ORIGEN2 codes [12] for various burnup levels and plutonium concentrations. An empirical equation was developed to model He production in MOX fuel containing either reactor grade plutonium or weapons grade plutonium. Diffusion and release of $\mathrm{He}$ from the pellet is assumed to be the same for $\mathrm{UO}_{2}$ and MOX. Only the He production rates are different which result in different He releases. Some fuel designs use a thin layer of $\mathrm{ZrB}_{2}$ applied to the surface of the pellets to act as an integral fuel burnable absorber (IFBA). The use of such coatings results in a large He production. An empirical correlation was fit to results from Monte Carlo N-Particle (MCNP) [13], a neutron transport code, for He production from IFBA liners. The He production rate is a function of the number of IFBA rods in a core, and the ${ }^{10} \mathrm{~B}$ enrichment. He is produced as the ${ }^{10} \mathrm{~B}$ burns out until there is no more ${ }^{10} \mathrm{~B}$ in the liners. The rate of ${ }^{10} \mathrm{~B}$ depletion is equal to the He production rate. The depletion of ${ }^{10} \mathrm{~B}$ is calculated in the code and the ${ }^{10} \mathrm{~B}$ enrichment at the end of the time step is used to calculate the He production for the next time step. It is assumed in the code that all He produced in the $\mathrm{ZrB}_{2}$ coatings is released directly to the rod free volume.

A new fission gas release model has been developed for FRAPCON-3.4a to accurately predict the gas in the grain matrix, the gas on the grain boundaries, and the released gas[14]. This model can be used to initialize the transient FGR model in FRAPTRAN 1.4. Although the new model provides better predictions of FGR at very high burnup (80-100 GWd/MTU) than the original model, the original model provides better predictions of the assessment data from 0-62 GWd/MTU. This model employs a grain growth model and a model for the formation of the high burnup rim structure. Similarly to the original model, this model uses a two-stage diffusion model to model diffusion of gas out of the grains to the grain boundary followed by saturation of the grain boundaries and release to the free volume. This model also includes a term to account for irradiation induced re-solution of gas on the grain boundaries back into the grains. This model provides good predictions of steady-state grain boundary gas concentrations and gas release from typical $\mathrm{LWR} \mathrm{UO}_{2}$ fuel up to $100 \mathrm{GWd}$ /MTU. Grain boundary gas concentration and high burnup FGR were areas where the previous model had not provided good predictions. The updated model predictions for some high burnup LWR [15] rods are shown in Fig. 1. This model is used to initialize a transient fission gas release model that has been included in FRAPTRAN 1.4 to predict gas release during a reactivity initiated accident (RIA). The new steady-state FGR model has been added as an option in FRAPCON-3.4a, but the original model (MASSIH) is retained as the default fission gas release (FGR) model because of its better predictions of ramped rods. The standard error of the MASSIH model relative to the assessment cases is $2.9 \%$ FGR for the steady state cases and 5.1\% FGR for the power ramped cases. For the new model, the standard error relative to the assessment cases is $3.6 \%$ FGR for the steady state cases and $7.5 \%$ FGR for the power ramped cases (underpredicts). Figure 2 shows the predicted vs. measured FGR for the steady state and power ramped rods using both models. Future work will be performed to improve the model predictions of the assessment data, while maintaining its ability to predict the grain boundary gas concentration.

\subsection{New Modeling Capabilities}

The option to model the cladding stress and strain using a finite element analysis (FEA) approach has been added to FRAPCON-3.4a. This model allows a user input of friction coefficient between the cladding and the fuel. Using this friction coefficient it is possible to better model the axial strain in the cladding during a power ramp. Several slow power ramps and RIA cases were modeled using the FEA model to determine what value of friction coefficient should be used. In order to obtain a best-estimate value of cladding axial strain a friction coefficient of 0.01 should be used in FRAPCON-3.4a with the FEA version when the rod-average burnup is below $40 \mathrm{GWd} / \mathrm{MTU}$. When the burnup is above $40 \mathrm{GWd} / \mathrm{MTU}$, a friction coefficient of 0.025 should be used in FRAPCON-3.4a with the FEA version. If the FRACAS-I option is used in the code, the prediction of axial strain will most likely be greater than the measured strain.

\subsection{Methodology Updates}

Fuel performance codes similar to FRAPCON-3.4a are 


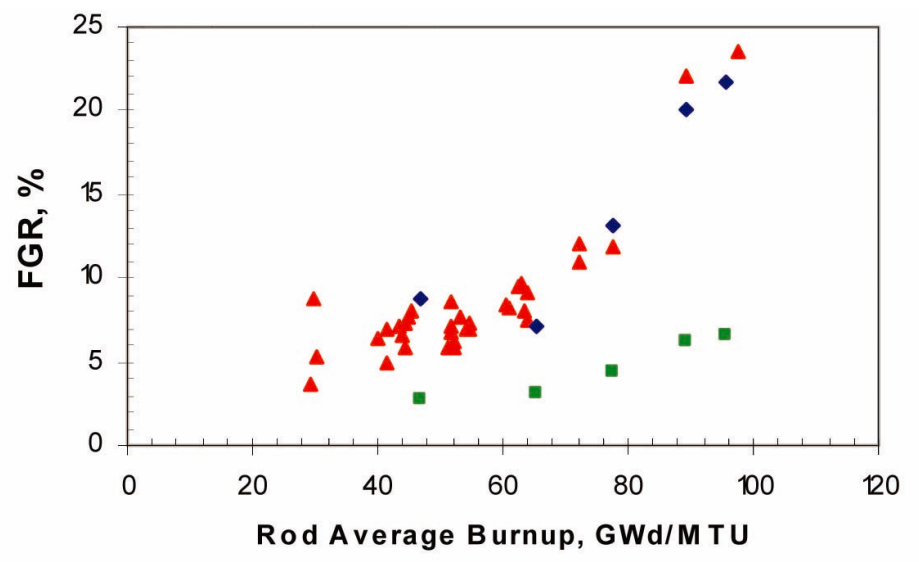

$\triangle$ Manzel Data • New Model Predictions - MASSIH model predictions

Fig. 1. Predicted and Measured FGR using the New and Original (MASSIH) FGR Models for High Burnup LWR Fuel Rods.
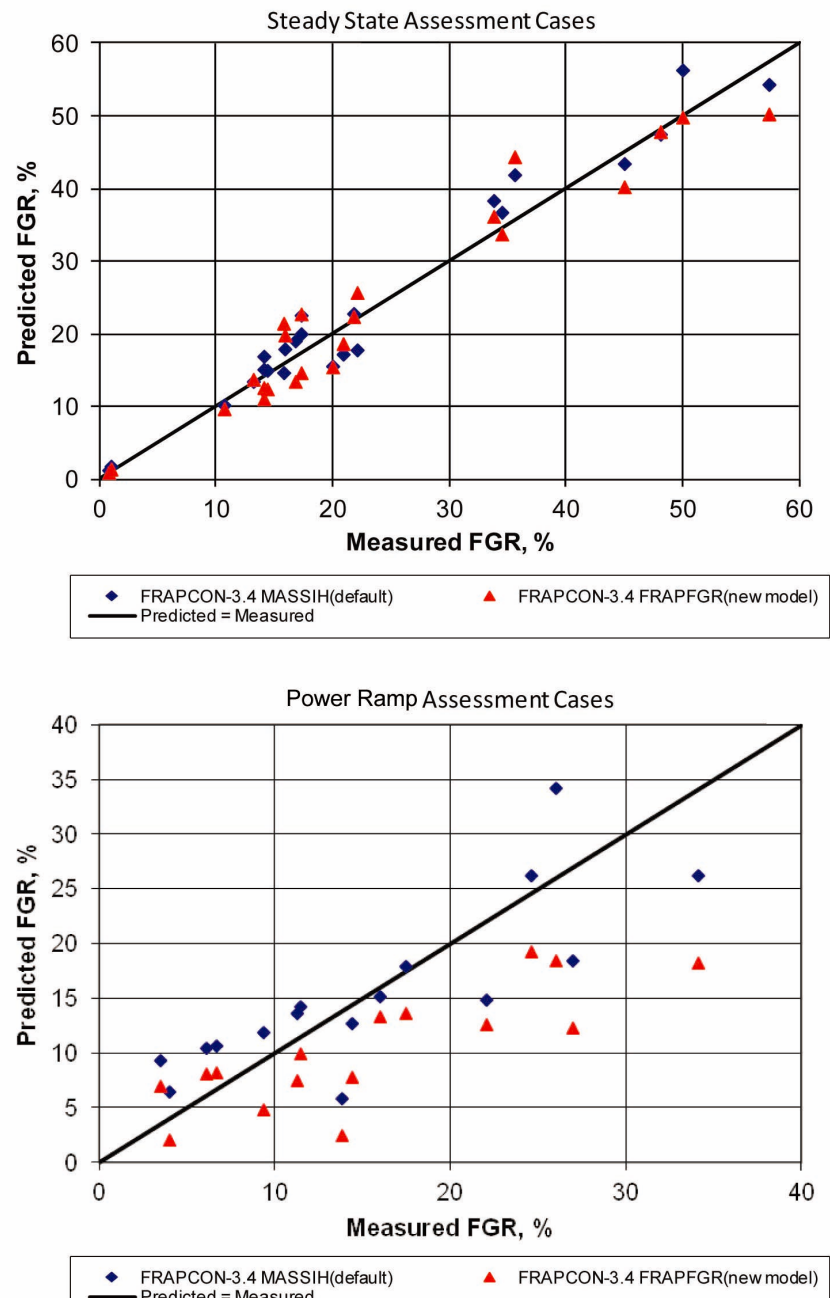

Fig. 2. Predicted vs. Measured FGR using the New and Original (MASSIH) FGR Model for Steady State and Power Ramped Assessment Cases 
used by industry to demonstrate margin to various specified acceptable fuel design limits (SAFDLs) such as fuel melting, maximum rod internal pressure, and maximum strain increment following normal operation or an anticipated operational occurrence (AOO). Typically, a statistical approach is used to demonstrate that there is a high degree of confidence given uncertainty in manufacturing parameters, model parameters, and power level that the rod with the maximum predicted value of the parameter of interest will not exceed some predetermined limit. Historically, industry has used a sum of square errors (SSE) approach to demonstrate compliance with these SAFDLs, however, recently, stochastic methodologies have been employed to demonstrate compliance.

The U.S. NRC uses the FRAPCON-3.4a code as an audit tool when reviewing submittals involving fuel performance codes and methodologies to demonstrate compliance with SAFDLs. In order to facilitate these reviews, capabilities to perform uncertainty analyses have been added to FRAPCON-3.4a. Recently, an uncertainty study was performed to determine the models and manufacturing parameters that have the largest impact on the FRAPCON-3.3 outputs of regulatory interest (maximum fuel centerline temperature, maximum rod internal pressure, and maximum strain increment)[16]. Eight models were identified as those necessary in a bounding design calculation in FRAPCON-3.3. The eight models selected were: fuel thermal conductivity, fuel thermal expansion, fission gas release, fuel swelling, irradiation creep, cladding thermal expansion, cladding corrosion, and cladding hydrogen pickup. These eight models were judged sufficient to generate a bounding design calculation to show the impact of model uncertainties (as opposed to input uncertainties) in the calculation of rod internal pressure, fuel centerline temperature, and cladding strain. Each of these models was compared to the data that were used to derive the model, as well as more recent data that have become available. The data that were used in these model comparisons were used to calculate a standard deviation for the model either in relative terms or absolute terms as appropriate. These standard deviations were hardwired into FRAPCON-3.4a, and the user is given the option to bias these individual models up or down by a fraction of the appropriate standard deviation. Using this capability, it is possible for the code user to calculate the effect of manufacturing uncertainties, model uncertainties, or power level uncertainties on the code outputs either individually or combined.

It would be very time consuming to manually perform a stochastic uncertainty analysis by hand, where each of the parameters are varied at random within their distribution and a large number of calculations are run to calculate an upper tolerance limit. In order to aid in performing such calculations, a stochastic framework has been developed for FRAPCON-3.4a. To use this capability, the user sets up a nominal case input file that the stochastic framework will read. The program will then display the nominal value for the manufacturing parameters from the input file and allow the user to specify an uncertainty distribution on each parameter. The program has a number of built in distributions to select from such as uniform, normal, triangle, and log-normal. The program will then allow the user to specify uncertainties on the selected models based on the hardwired standard deviations for each and to specify uncertainties on the power history. The program allows for uncertainties in the steady-state power histories because there are uncertainties in the calculated power histories and actual operation. The program also allows the user to add an AOO power pulse following any time step with uncertainties on the pulse duration and power level.

The stochastic framework program creates a userspecified number of FRAPCON-3.4a input decks with randomly selected parameters from the specified distributions. The program then consecutively runs each of these input decks, or "realizations," and reads the output from each to collect the maximum centerline temperature, maximum rod internal pressure, and maximum cladding strain increment from each realization. Based on this information, the program can calculate various upper tolerance limits at various confidence levels. In addition, the output distributions can be examined to determine if there are correlations between various inputs or between inputs and outputs. Figure 3 shows output distributions for a sample case where manufacturing, model, and power uncertainties were applied. Figure 4 shows some of the other plots that can be used to analyze the results. The QQ-Plot can be used to determine if the output distribution is normally distributed. In this example, the hypothesis of normality should be rejected ( $p$-value is less than 0.05). Also, the output values may be plotted as a function of the input values. In this example it can be seen that increases in power history cause increases in maximum centerline temperature, while the maximum centerline temperature seems relatively insensitive to the uncertainty in the cladding creep model.

This updated methodology greatly enhances the ability of the NRC to perform audits on vendor methodologies that include estimates of uncertainties in calculated results as well as focuses development efforts on data collection and model development in areas that have the biggest impact on the code outputs. The stochastic framework program has not been described elsewhere and is still under final development at PNNL. A version of this program can be made available to members of the users group upon request.

\section{ASSESSMENT OF FRAPCON-3.4A}

Prior to the release of FRAPCON-3.4a, an assessment of FRAPCON-3.3 was performed on the individual model predictions such as fuel thermal conductivity and other 

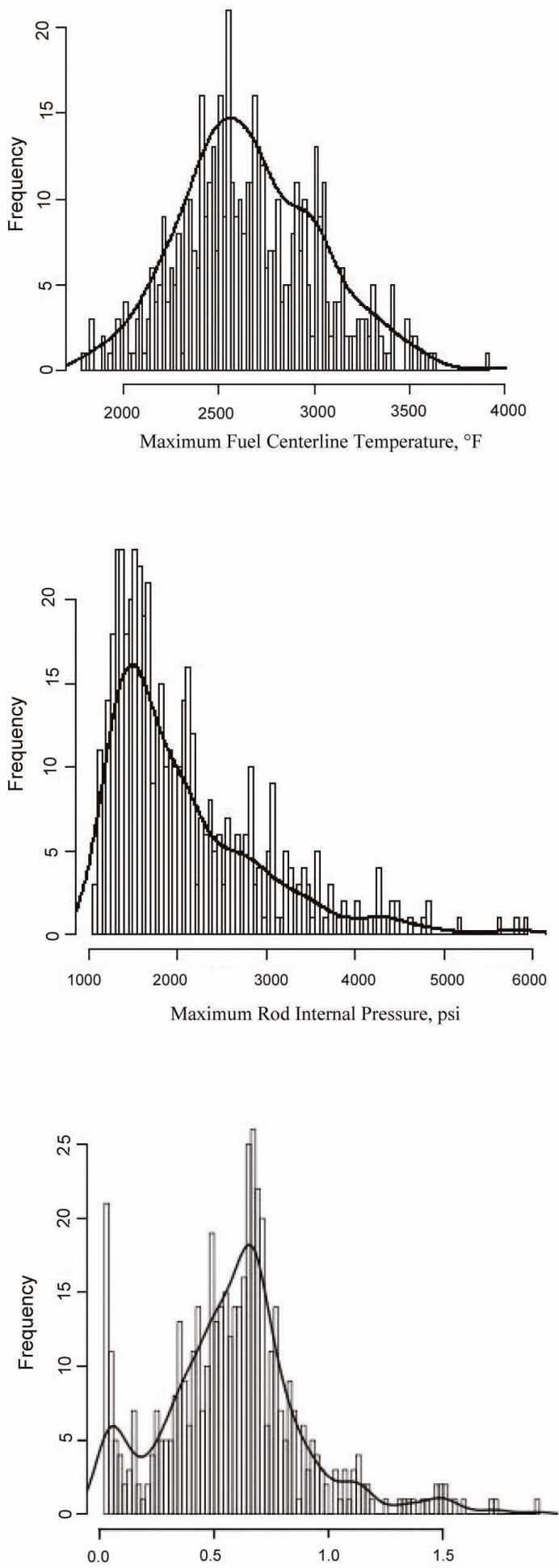

Maximum Cladding Permanent Hoop Strain Increment, \%

Fig. 3. Output Distributions on Maximum Fuel Centerline Temperature, Maximum Rod Internal Pressure and Maximum Cladding Permanent Hoop Strain Increment for 500

Realizations of a Sample Case with Normal Distributions on Manufacturing, Model and Power Uncertainties.

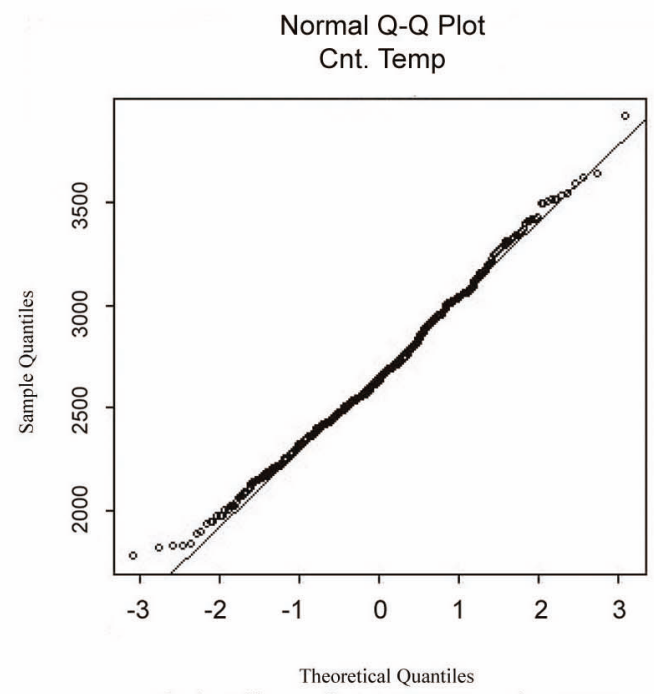

Shapiro-Wilk normality test, $\mathrm{W}=0.993$; $\mathrm{p}$-values $=0.0193$
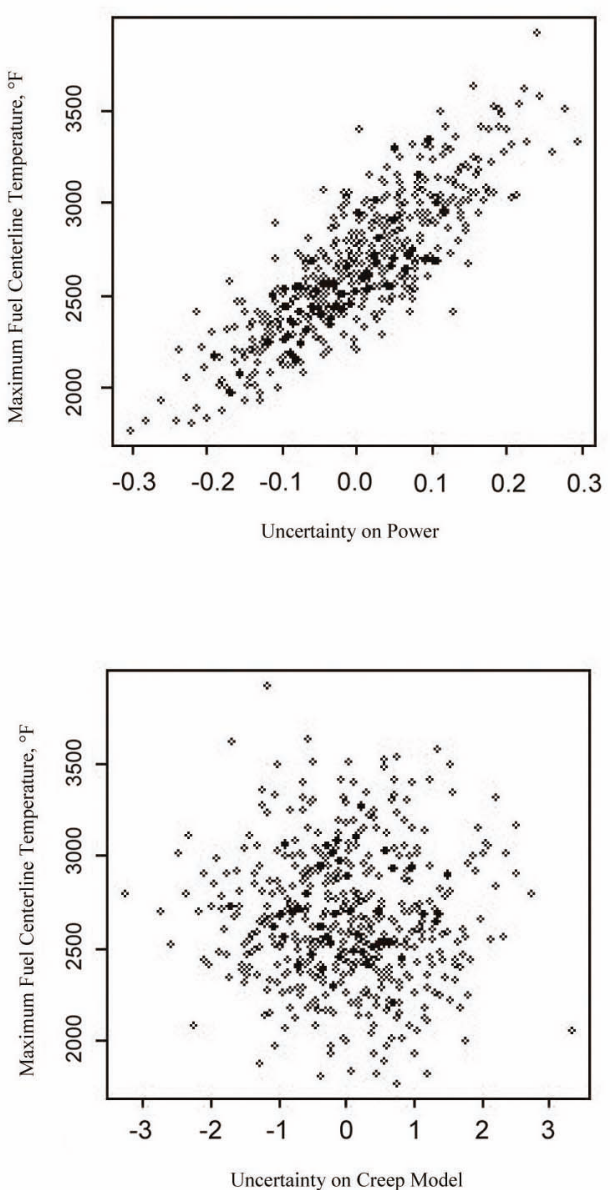

Fig. 4. Additional Output plots for Maximum Fuel Centerline Temperature for 500 Realizations of a Sample Case with Normal Distributions on Manufacturing, Model and Power Uncertainties. 
material properties and the integral model predictions such as centerline temperature and rod internal pressure to address concerns that FRAPCON-3 is conservatively biased in its predictions[16]. It has been noted that the original fuel performance codes used by the NRC, the predecessors of FRAPCON-3 and FRAPTRAN were intrinsically conservative [16]. In fact, the current version of FRAPCON-3 continues to provide conservative options (although these options are no longer used or recommended by PNNL). Despite efforts to update the codes and the models over the past 15 years, the codes are still considered by some to be not just optionally but intrinsically conservative. In order to quantitatively determine if these codes are biased, FRAPCON-3.3 and FRAPTRAN 1.3 were examined to determine if the individual material property models or code outputs were biased relative to the available data.

Each individual model and type of code prediction was examined and compared to the data that was used to develop the model. In addition, a brief literature search was performed to determine if more recent data have become available since the original model development for model comparison. If new data were discovered, these data were compared to the models and code predictions in FRAPCON-3.3 and FRAPTRAN-1.3 in order to determine if the model was biased. Models or integral effect prediction found to be biased relative to the data were updated and corrected in FRAPCON-3.4a and FRAPTRAN 1.4. Areas where modeling may be lacking were noted for further model development.

The conclusion of this assessment was that both FRAPCON-3.3 and FRAPTRAN-1.3 provide best-estimate predictions of fuel and cladding temperatures and cladding stress and strain[16]. Several areas were identified as areas that should be re-examined and new models developed to improve the model's predictive capability. These areas were addressed in FRAPCON-3.4a.

When FRAPCON-3.4a was released, the code was assessed against 133 well-characterized fuel rods [17]. These include 45 test rods that experienced end of life (EOL) power ramps (used for FGR and cladding hoop strain) and 88 "steady-state" cases including $\mathrm{UO}_{2}, \mathrm{MOX}$, and $\mathrm{UO}_{2}-\mathrm{Gd}_{2} \mathrm{O}_{3}$ rods used for fuel temperatures and FGR. Five rods from the primary set were used to assess FRAPCON-3.4a predictions of EOL void volume. The cases selected include full-length power reactor rods and shorter test reactor rods. A mix of test reactor and power reactor rods was also used to assess the fuel volume change due to densification and swelling. The FRAPCON-3.4a model for cladding waterside oxidation was evaluated against BWR Zircaloy-2 and PWR Zircaloy-4, ZIRLO ${ }^{\text {TM }}$, and M5TM rod data. The FRAPCON-3.4a predictions of cladding hoop strain were assessed against 27 BWR and PWR rods that were power ramped in various test reactors.

The following conclusions about FRAPCON-3.4a were made as a result of this assessment:[17]

Thermal: Comparisons were made for $\mathrm{BOL} \mathrm{UO}_{2}$ temperature measurements and $\mathrm{UO}_{2}, \mathrm{MOX}$, and $\mathrm{UO}_{2-}$ $\mathrm{Gd}_{2} \mathrm{O}_{3}$ temperature measurements as a function of burnup. Overall, FRAPCON-3.4a gave reasonable predictions of fuel centerline temperature for fuel rods with $\mathrm{UO}_{2}, \mathrm{MOX}$, and $\mathrm{UO}_{2}-\mathrm{Gd}_{2} \mathrm{O}_{3}$ fuel (standard deviation of $5 \%$ relative). Figures 5,6 , and 7 give the predicted vs. measured temperature for and $\mathrm{UO}_{2}, \mathrm{MOX}$,

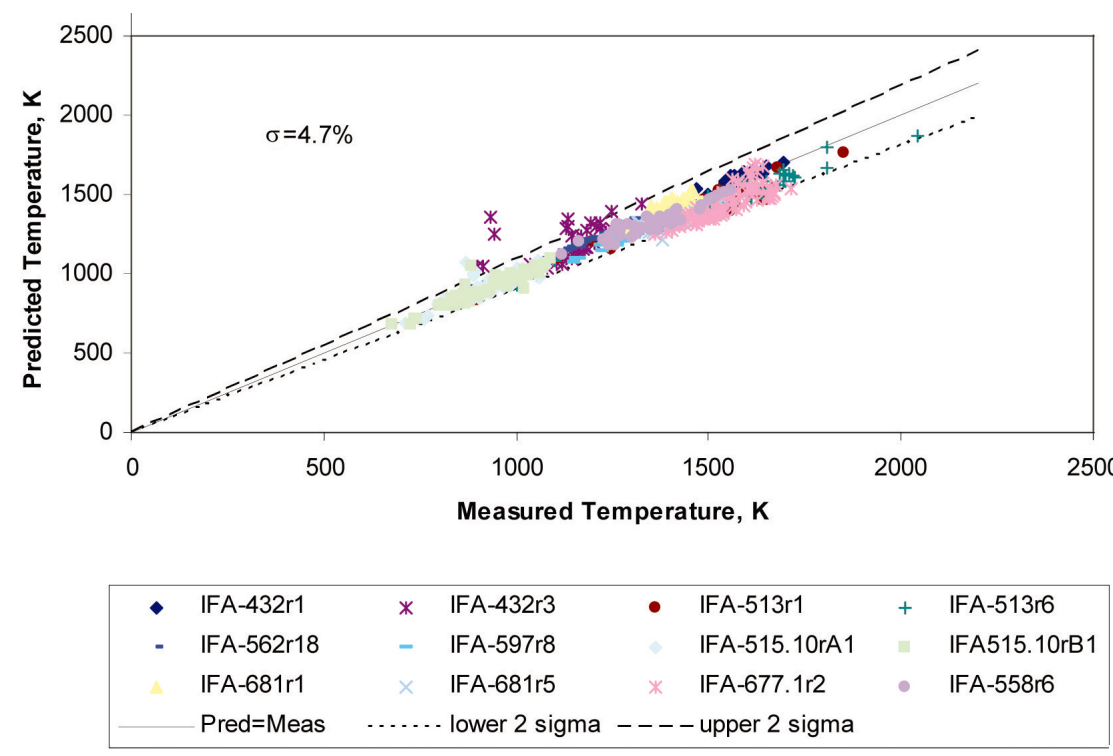

Fig. 5. Measured and Predicted Centerline Temperature for the $\mathrm{UO}_{2}$ Assessment Cases Throughout Life 


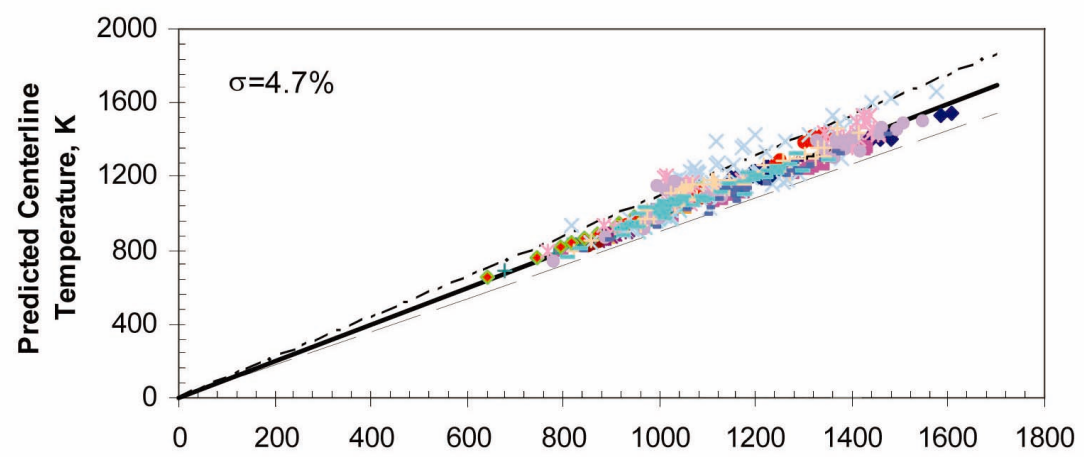

Measured Centerline Temperature, $\mathrm{K}$

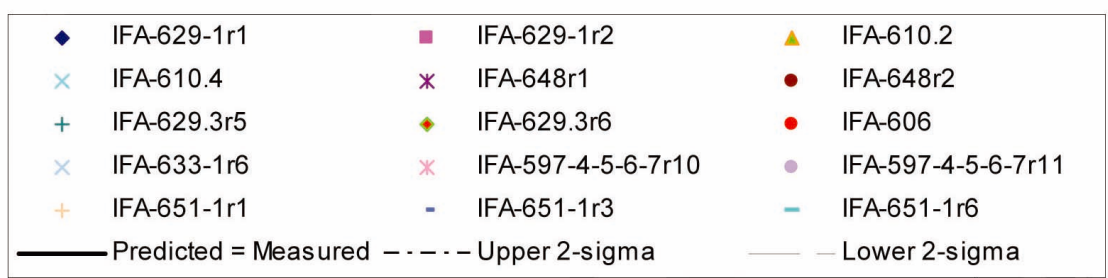

Fig. 6. Measured and Predicted Centerline Temperature for the MOX Assessment Cases Throughout Life

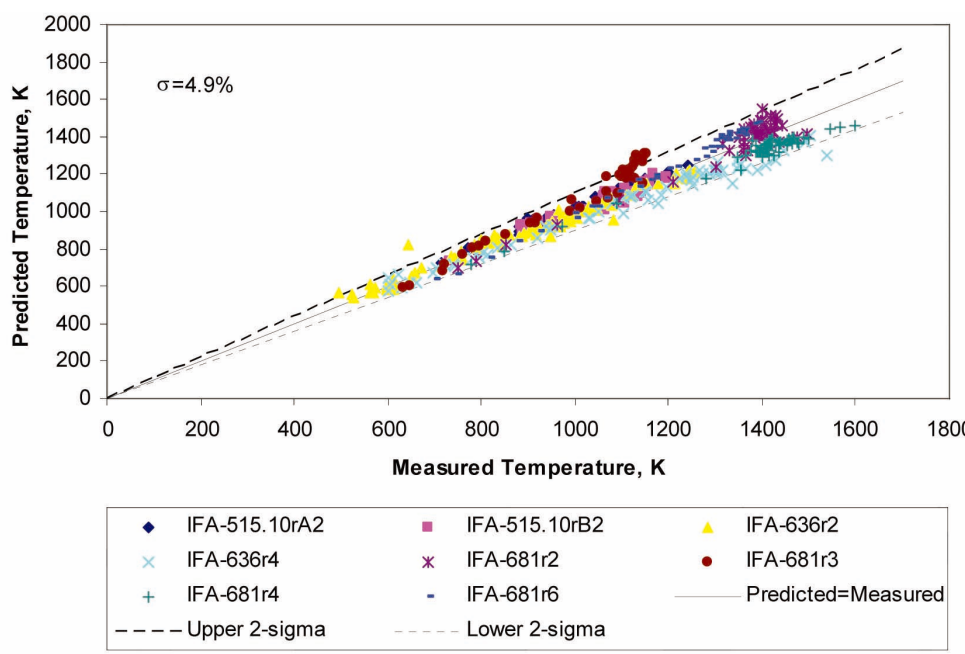

Fig. 7. Measured and Predicted Centerline Temperature for the $\mathrm{UO}_{2}-\mathrm{Gd}_{2} \mathrm{O}_{3}$ Assessment Cases Throughout Life

and $\mathrm{UO}_{2}-\mathrm{Gd}_{2} \mathrm{O}_{3}$ rods respectively.

Fission Gas Release: Comparisons were made for the $\mathrm{UO}_{2}$ and MOX FGR measurements for rods with widely varying power levels and burnups. Overall, FRAPCON-3.4a gave reasonable predictions (standard error of 5-6\% FGR absolute) of fission gas release for fuel rods with $\mathrm{UO}_{2}$ and MOX fuel. FRAPCON-3.4a overpredicts MOX rods subjected to a power ramp and underpredicts MOX rods with burnup greater than $60 \mathrm{GWd} / \mathrm{MTU}$. Figure 8 gives predicted minus measured FGR for and $\mathrm{UO}_{2}$ and $\mathrm{MOX}$ rods using the Massih model. The ATR data noted in Figure 8 has a large degree of uncertainty in the reported power level which gives more uncertainty in the prediction of FGR. If the ATR data is excluded and overall standard error for $\mathrm{UO}_{2}$ and MOX FGR under steady state and power ramp conditions of $5.7 \%$ FGR is calculated. Standard 


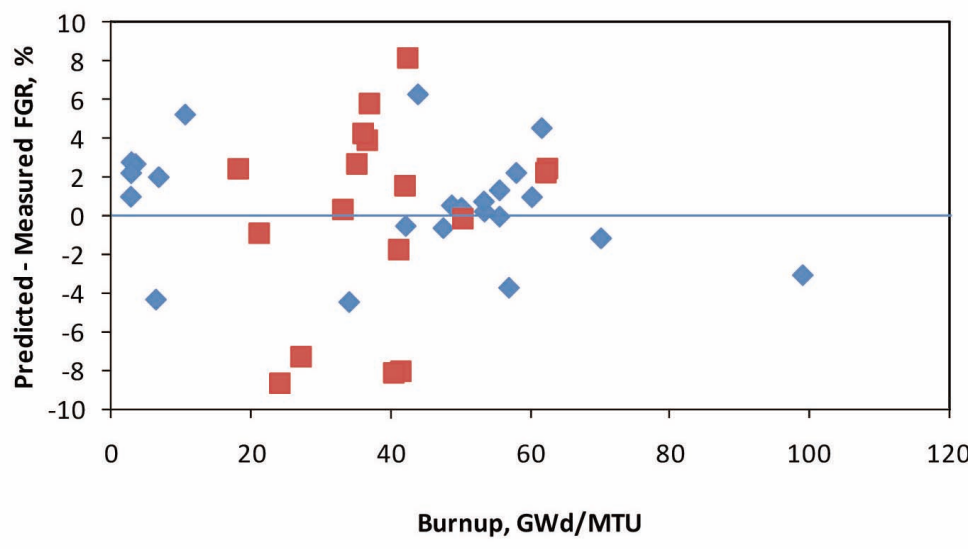

$\checkmark$ UO2 steady-state $\quad$ UO2 power ramp

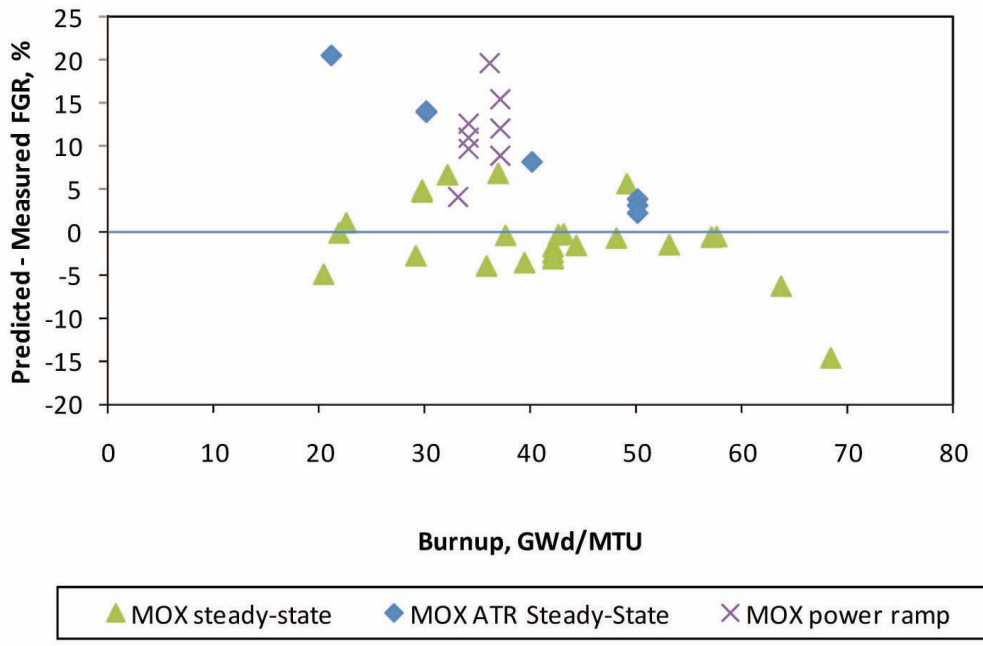

Fig. 8. Prediced Minus Measured FGR vs. Burnup for $\mathrm{UO}_{2}$ and $\mathrm{MOX}$ Assessment Cases.

errors of $2.6 \% \mathrm{FGR}$ and $4.5 \% \mathrm{FGR}$ are calculated for $\mathrm{UO}_{2}$ and MOX steady state FGR predictions respectively. Standard errors of $5.1 \%$ FGR and $13.4 \%$ FGR are calculated for $\mathrm{UO}_{2}$ and MOX power ramp FGR predictions respectively.

Internal Void Volume: Comparisons were made to data from two commercial reactor and three test reactor fuel rods. The code predicted the two commercial rods well but overpredicted the BR-3 test rod data by approximately $15 \%$ (relative) on average.

Cladding Corrosion: Comparisons were made to data from two commercial BWR rods with Zircaloy-2 cladding, two commercial PWR rods with Zircaloy-4 cladding, two commercial PWR rods with ZIRLO $^{\mathrm{TM}}$ cladding, and one commercial PWR rod with $\mathrm{M}^{\mathrm{TM}}$ cladding. The oxide thickness predictions were very good and tend to bracket the data.

Cladding Hoop Strain: The original hoop strain assessment cases that were available up to a burnup of around $45 \mathrm{GWd} / \mathrm{MTU}$ demonstrated that, on average, FRAPCON-3.4a slightly overpredicts cladding hoop strain by $0.1 \%$ strain. On average, above $45 \mathrm{GWd} / \mathrm{MTU}$ FRAPCON-3.4a underpredicts cladding permanent hoop strain by $0.3 \%$. The measured and predicted hoop strains are shown in Figure 9. 


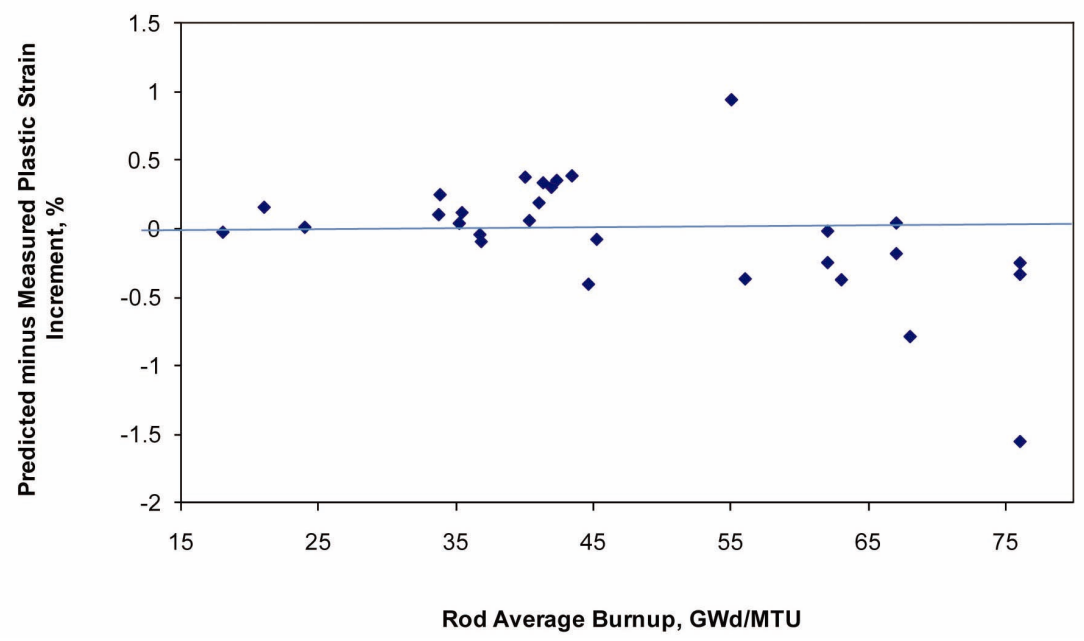

Fig. 9. Predicted Minus Measured Permanent Hoop Strain as a Function of Burnup

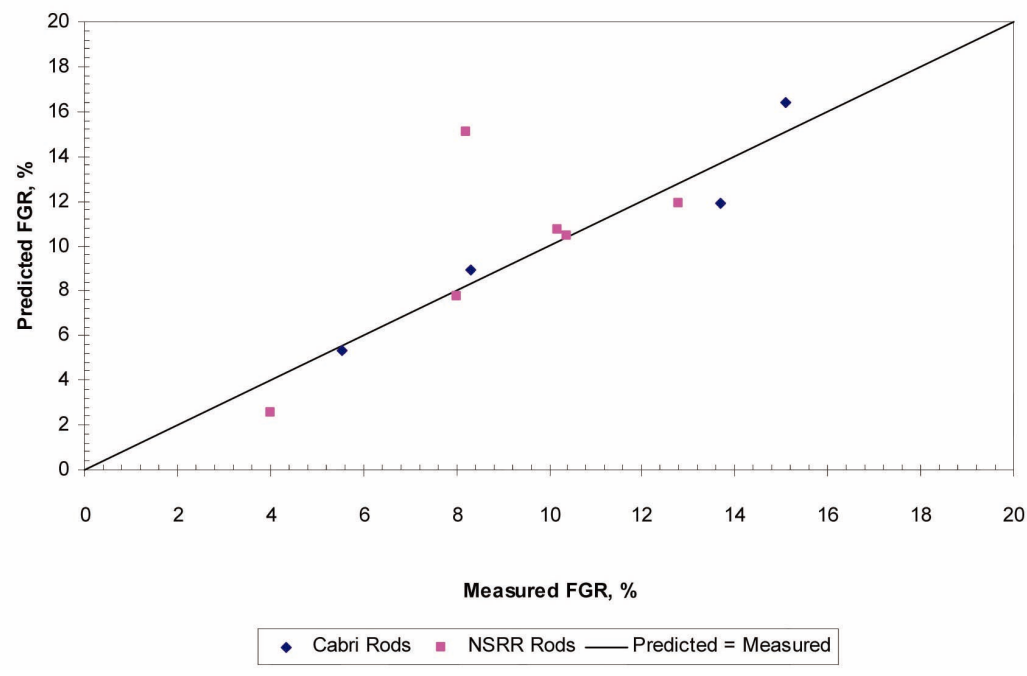

Fig. 10. FRAPTRAN 1.4 Predictions of RIA FGR for CABRI and NSRR $\mathrm{UO}_{2}$ Rods

\section{RECENT UPDATES TO FRAPTRAN 1.4}

Several significant changes were made in FRAPTRAN 1.4 to improve its predictive abilities relative to FRAPTRAN 1.3. These changes are briefly described in this section and are described in more detail elsewhere[4], and in the FRAPTRAN 1.4 description document [2].

For consistency, the thermal conductivity model for mixed-oxide fuels and the improved $\mathrm{UO}_{2}$ fuel thermal expansion model in FRAPCON-3.4a described in Section 3 were added to FRAPTRAN 1.4. The cladding FEA model in FRAPCON-3.4a described in Section 3 is also included in FRAPTRAN 1.4 and the recommendations for friction coefficient apply to FRAPTRAN 1.4 as well. Finally, the modified gas conductivity equations in FRAPCON-3.4a described in Section 3 were added to FRAPTRAN 1.4. These changes have more impact in FRAPTRAN 1.4 than in FRAPCON-3.4a because of the greater temperatures 
experienced during transient cases.

In order to better model the stress and strain during ballooning, FRAPTRAN 1.4 was modified such that when ballooning is predicted to begin in one node, no further strain is calculated in the axially adjacent non-ballooning nodes. The resulting peak strain is calculated by the BALON2 [18] subcode and is used as the hoop strain for the ballooning node. Previously, in FRAPTRAN 1.3, the BALON2 model was only used to calculate flow blockage and not hoop strain. Failure is assumed to occur when the cladding true hoop stress exceeds an empirical stress limit. This limit is a function of temperature, cold work and fluence. However, for the temperatures and times applicable to loss-of-coolant accidents (LOCA), (on the order of 10 seconds) the fluence and cold work effects are predicted by the FRAPTRAN 1.4 annealing model CANEAL[19] to be annealed out. After this change was made, the predicted burst stress compared well to the ballooning data LOCA burst tests. However, the permanent hoop strain at failure was often overpredicted. In order to better predict the permanent hoop strain at failure, a strain limit was imposed over the temperature range of $940 \mathrm{~K}$ to $1600 \mathrm{~K}$. Therefore, failure is assumed to occur if the cladding true hoop stress exceeds the stress limit, or if the cladding permanent hoop strain exceeds the strain limit. With these two limits in place, FRAPTRAN 1.4 can predict both cladding failure stress and strain consistently with the data and the previously published curves from NUREG-0630 [20].

FRAPTRAN 1.3 included a failure model to predict cladding failure during RIA. This model assumes the cladding fails when the predicted cladding plastic strain exceeds the model prediction of uniform elongation. This model is a function of temperature and hydrogen concentration. More recent data have indicated that the cladding will fail in a brittle manner with little or no plastic deformation if there are high hydrogen concentrations in the cladding. It was determined that this brittle behavior starts between 650 and $900 \mathrm{ppm}$ of excess hydrogen. A second failure model was added to FRAPTRAN 1.4 such that if the cladding excess hydrogen concentration is greater than $650 \mathrm{ppm}$, the cladding is assumed to fail if the plastic strain exceeds $0.05 \%$. It was found that using this failure model, the failure or non-failure for the 33 RIA tests in the assessment database is correctly predicted for 30 tests. For the remaining three tests, the deposited energy is within $5-10 \mathrm{cal} / \mathrm{g}$ of the enthalpy required to correctly predict failure or non failure.

A new transient FGR model has been added to FRAPTRAN 1.4 and is initialized using the new steady state FGR model in FRAPCON-3.4a discussed in Section 3. This model was assessed against RIA tests that did not experience cladding failure. It was found that the FGR for non-failed $\mathrm{UO}_{2}$ rods from the Cabri and NSRR tests was predicted well. Figure 10 shows the predicted vs. measured FGR from non-failed rods. This model was not assessed against LOCA test data, as most of the LOCA tests experience cladding failure so that it is not possible to measure the gas release following the test.

The cladding to coolant heat transfer models in FRAPTRAN 1.3 were critically reviewed from a thermalhydraulic standpoint[2]. As a result of this review, several heat transfer correlations were removed and several correlations were added to FRAPTRAN 1.4. In addition, user guidelines were prepared and are included in the input instructions. These changes make the thermal hydraulic models in FRAPTRAN 1.4 more robust and more applicable to different accident scenarios. In addition, the user guidelines and default correlations make it easier for a user to set up an input file without advanced thermal hydraulic experience.

\section{ASSESSMENT OF FRAPTRAN 1.4}

The assessment performed on FRAPCON-3.3 to determine if the code predictions are conservatively biased was also performed on FRAPTRAN 1.3 [16]. The conclusion of this assessment was that both FRAPCON3.3 and FRAPTRAN-1.3 provide best-estimate predictions of fuel and cladding temperatures and cladding stress and strain [16]. Several areas were identified as areas that should be re-examined and new models developed to improve the model's predictive capability. These areas were addressed in FRAPTRAN 1.4.

When FRAPTRAN 1.4 was released, the code was assessed against data from selected integral irradiation experiments and post-irradiation examination programs [21]. The cases used for code assessment were selected on the criteria of having well-characterized design and operational data and spanning the ranges of interest for both design and operating conditions. Two principal sets of data were used: 1) data from recent RIA test programs and 2) data from LOCA test programs. The code assessment database consists of 43 integral assessment cases.

The comparisons of the FRAPTRAN 1.4 calculations to the experimental data demonstrated that FRAPTRAN 1.4 generally performed well in the comparison to data. Additional conclusions from this code-data assessment are as follows [21]:

RIA Cases: FRAPTRAN 1.4 predicts reasonable values of cladding hoop strain for cases with less than $2 \%$ hoop strain. For cases with greater than $2 \%$ measured hoop strain, FRAPTRAN 1.4 underpredicts the measured hoop strain. FRAPTRAN 1.4 provides a best-estimate prediction of cladding failure (30 of 33 rods with failure or non-failure correctly predicted). FRAPTRAN 1.4 predicts $\mathrm{UO}_{2}$ transient FGR well, with a standard deviation of $2.5 \%$ FGR absolute and a slight overprediction on average of $0.48 \%$ FGR absolute. 
LOCA Cases: FRAPTRAN 1.4 predicts the occurrence of cladding failure well, and incorrectly predicted only one rod within the assessment cases (failure was predicted when none was observed). FRAPTRAN 1.4 often predicts failure before it was actually observed, but this may be because of an external gas plenum volume (not in the core) in the test that FRAPTRAN 1.4 is unable to accurately predict because it assumes the plenum is in the core as it is for commercial fuel. FRAPTRAN 1.4 predicts reasonable values of cladding hoop strain for rods before and after ballooning and burst, with predicted values 1 to $14 \%$ strain absolute higher than observed. Given the scatter in burst strain measurements from similar rods subjected to similar LOCA burst tests ( $\pm 50 \%$ strain), this overprediction is reasonable and conservative from a flow blockage standpoint. FRAPTRAN 1.4 predicts reasonable values of high-temperature corrosion thickness following a LOCA.

\section{PLANS FOR IMPROVEMENTS TO FRAPCON-3 AND FRAPTRAN}

The NRC is currently considering implementing hydrogen based regulations for several accident scenarios such as LOCA and RIA. Many vendor fuel performance codes do not contain an approved hydrogen pickup model. The NRC steady state fuel performance code, FRAPCON$3.4 \mathrm{a}$, currently contains hydrogen pickup models for Zircaloy-2 cladding under BWR conditions and for Zircaloy-4, ZIRLOTM, and M5 ${ }^{\mathrm{TM}}$ cladding under PWR conditions. In anticipation of the NRC using the hydrogen pickup models in FRAPCON-3.4a, the models were reevaluated against current data and modifications to these models were suggested [22]. These updated models will be included in FRAPCON-3.5.

The NRC currently uses a visualization tool called SNAP [23] in the development of inputs for some of their system codes. Since there are many users at NRC who are familiar with SNAP, a plug-in that supports the latest versions of FRAPCON-3 and FRAPTRAN will be developed so these users will be able to more easily learn how to use FRAPCON-3 and FRAPTRAN. In addition, work will continue to improve the Microsoft EXCEL® input generators and output visualization tools that are currently in use to aid in the set-up and visualization of input files and in the analysis of the code predictions.

The cladding mechanical properties at normal operating temperatures and at high temperatures relevant to LOCA currently use generic Zircaloy properties. In the past, assessments have shown these generic properties to be adequate to predict the behavior of advanced alloys such as ZIRLO $^{\mathrm{TM}}$, Optimized ZIRLO ${ }^{\mathrm{TM}}$, and M5 ${ }^{\mathrm{TM}}$. More high burnup data and LOCA burst test data from these advanced alloys is available now and an assessment will be performed to determine if these advanced alloys behave significantly differently than Zircaloy. If so, alloy specific models for areas where the alloys behave differently will be developed and included in new versions of FRAPCON-3 and FRAPTRAN.

The FRAPCON-3 code is designed to model steady state behavior and can model the response to relatively long transients (on the order of hours), by modeling phenomena important on this time scale. The FRAPTRAN code is designed to model transient behavior and specifically the response to transients of relatively short time duration between milliseconds to several seconds. Of recent interest are transients on an intermediate time scale of seconds to minutes, such as those expected during AOO. The need to model additional phenomena, such as fission gas swelling, fission gas release and cladding creep, in each code will be evaluated by assessing FRAPCON-3 and FRAPTRAN's ability to predict stress and strain data generated by integral ramp tests simulating AOO transients. FRAPCON-3.4a does not include a cladding failure model. Neither FRAPCON-3.4a nor FRAPTRAN 1.4 currently has a pellet cladding interaction (PCI) failure model. Available data will be evaluated to determine if a correlation of stress and strain values to failure under PCI conditions can be developed. If appropriate, a cladding failure limit based on cladding stress and/or strain under slow ramp conditions will be developed and a FRAPCON-3 failure model for stress corrosion cracking (SCC) (PCI is really a SCC type failure) and delayed hydride cracking will be developed.

To improve the ability of FRAPTRAN to model LOCA tests, several advanced LOCA modeling capabilities will be added. A model for axial fuel relocation following ballooning and burst will be developed for a future version of FRAPTRAN. Changes to the allowed geometry will be made to allow FRAPTRAN to model LOCA tests including tests that have a large gas space connected to the fuel rod that resides outside the reactor core. Finally, an assessment of the impact of CRUD (a mixture of different deposits on the rod) on LOCA performance will be evaluated and improvements will be made to allow FRAPTRAN to be initialized with values of CRUD thickness from the steady-state irradiation calculated with FRAPCON-3.

\section{FRAPCON-3/FRAPTRAN USERS' GROUP}

PNNL distributes the executables and source code for FRAPCON-3 and FRAPTRAN and maintains a FRAPCON3 and FRAPTRAN user group. The users group consists of about 30 international organizations and universities. The users' group meets every one to two years so that users can be informed of recent code development and plans for future improvements. In addition, users have the opportunity to share with PNNL and the rest of the 
group, the activities that they have been performing with the codes. The users provide valuable debugging and suggestions for improvements to the codes.

Membership is open to any organization, although it is subject to approval by the U.S. NRC and the U.S Department of Energy. A nominal fee is charged to obtain the code and a yearly fee is charged after that for membership in the users' group. Membership includes participation in users' group meetings and on-call assistance from PNNL staff. For more information regarding joining the users' group, see http://frapcon.labworks.org/.

\section{SUMMARY}

FRAPCON-3.4a and FRAPTRAN 1.4 are steady-state and transient fuel performance codes that provide best estimate predictions of LWR and HBWR fuel rod performance under normal operating conditions, operational occurrences, and accident conditions. These codes contain models for $\mathrm{UO}_{2}, \mathrm{UO}_{2}-\mathrm{Gd}_{2} \mathrm{O}_{3}$, IFBA, and $\mathrm{MOX}$ fuel and Zircaloy-2, Zircaloy-4, ZIRLO ${ }^{\mathrm{TM}}$ and M5 ${ }^{\mathrm{TM}}$ cladding. The code predictions have been assessed against a wide variety of experimental data up to a rod-average burnup of at least $62 \mathrm{GWd} / \mathrm{MTU}$, which is the licensing limit in the U.S. Recent new modeling capabilities have improved the codes' predictions and extended their ranges of applicability.

\section{ACKNOWLEDGEMENTS}

PNNL develops and maintains the fuel performance codes, FRAPCON-3 and FRAPTRAN for the U.S. NRC under contract JCN V6197.

Pacific Northwest National Laboratory is operated by Battelle Memorial Institute for the U.S. Department of Energy under contract DE-AC05-76RL01830.

\section{REFERENCES}

[ 1 ] K.J. Geelhood, W.G. Luscher, and C.E. Beyer. FRAPCON3.4: A Computer Code for the Calculation of Steady-State, Thermal-Mechanical Behavior of Oxide Fuel Rods for High Burnup, NUREG/CR-7022, Vol. 1, PNNL-19418, Vol. 1, Pacific Northwest National Laboratory, Richland, Washington (2011).

[2] K.J. Geelhood, W.G. Luscher, C.E. Beyer, and J.M. Cuta. FRAPTRAN 1.4: A Computer Code for the Transient Analysis of Oxide Fuel Rods, NUREG/CR-7023, Vol. 1, PNNL-19400, Vol. 1, Pacific Northwest National Laboratory, Richland, WA (2011)

[3] W.G. Luscher and K.J. Geelhood Material Property Correlations: Comparisons between FRAPCON-3.4, FRAPTRAN 1.4, and MATPRO, NUREG/CR-7024, PNNL19417, Pacific Northwest National Laboratory, Richland, WA (2011).

[ 4 ] K.J. Geelhood, C.E. Beyer, and W.G. Luscher, "New Release of Fuel Performance codes, FRAPCON-3.4 and FRAPTRAN
1.4," Proceedings of TopFuel 2009, Paris France (2009).

[5] K Lafchiev and T Tverberg, "Review of the HBWR database on fuel swelling behaviour," HWR-822, Enlarged Halden Programme Group meeting, Lillehammer (2005).

[6] M Limbäck and T. Andersson, "A Model for Analysis of the Effect of Final Annealing on the In- and Out-of-Reactor Creep Behavior of Zircaloy Cladding," Zirconium in the Nuclear Industry: Eleventh International Symposium, ASTM STP 1295, E.R. Bradley and G.P. Sabol, Eds., American Society for Testing and Materials, pp. 448-468 (1996).

[ 7 ] Y. Matsuo, "Thermal Creep of Zircaloy-4 Cladding under Internal Pressure," Journal of Nuclear Science and Technology, 24, 2, 111-119 (1987).

[ 8 ] D.G. Franklin, G.E. Lucas, A.L. Bement, Creep of Zirconium Alloys in Nuclear Reactors, ASTM STP 815, American Society for Testing and Materials, West Conshohocken, PA (1983).

[ 9 ] K. Lassmann, C. O'Carroll, J. van de Laar, and C.T. Walker, "The Radial Distribution of Plutonium in High Burnup $\mathrm{UO}_{2}$ Fuels", Journal of Nuclear Materials, 208, 223-231 (1994).

[10] K. Lassmann, C.T. Walker, and J. van de Laar, "Extension of the TRANSURANUS Burnup Model to Heavy Water Reactor Conditions", Journal of Nuclear Materials, 255, 222-233 (1998)

[11] WIMS: A Modular Scheme for Neutronics Calculations, ANSWERS/WIMS (99) 9, The ANSWERS Software Package, AEA Technology.

[12] S. B. Ludwig, J. P. Renier, Standard-and Extended-Burnup PWR and BWR Reactor Models for the ORIGEN2 Computer Code, ORNL/TM-11018 (December 1989).

[13] X-5 Monte Carlo Team, "MCNP - A General N-Particle Transport Code, Version 5 - Volume I: Overview and Theory", LA-UR-03-1987, Los Alamos National Laboratory (April, 2003)

[14] K.J. Geelhood and C.E. Beyer, “A New Fission Gas Release Model for Predicting Gas Release during Steady State and Slow Power Ramps and for Initializing Fast Transients," Proceedings of the 2007 International LWR Fuel Performance Meeting, San Francisco, California (2007).

[15] R. Manzel and C.T. Walker, "EPMA and SEM of fuel samples from PWR rods with an average burn-up of around $100 \mathrm{MWd} / \mathrm{kgHM}$ ", Journal of Nuclear Materials, 301, pp. 170-182 (2002).

[16] K.J. Geelhood, W.G. Luscher, C.E. Beyer, D.J. Senor, M.E. Cunningham, D.D. Lanning, and H.E. Adkins. Predictive Bias and Sensitivity in NRC Fuel Performance Codes, NUREG/CR-7001, PNNL-17644, Pacific Northwest National Laboratory, Richland, WA (2009).

[17] K.J. Geelhood, W.G. Luscher, and C.E. Beyer, FRAPCON3.4: Integral Assessment, NUREG-CR-7002 Vol. 2, PNNL19418, Vol. 2, Pacific Northwest National Laboratory, Richland, Washington (2011).

[18] D.L. Hargman, Zircaloy Cladding Shape at Failure (BALON2), EGG-CDAP-5379, Idaho National Engineering Laboratory 1981.

[19] D. L. Hagrman, G.A. Reymann, and R.E. Mason, MATPROVersion 11 (Revision 2). A Handbook of Materials Properties for Use in the Analysis of Light Water Reactor Fuel Rod Behavior, NUREG/CR-0479 (TREE-1280, Rev. 2), EG\&G 
Idaho, Inc., Idaho Falls, ID (1981)

[20] D.A. Powers and R.O. Meyer, Cladding Swelling and Rupture Models for LOCA Analysis, NUREG-0630, U.S. Nuclear Regulatory Commission (1980).

[21] K.J. Geelhood, W.G. Luscher, and C.E. Beyer. 2010. FRAPTRAN 1.4 Integral Assessment, NUREG/CR-7023, Vol. 2, PNNL-19400, Vol. 2, Pacific Northwest National
Laboratory, Richland, WA.

[22] K.J. Geelhood and C.E. Beyer "Hydrogen Pickup Models for Zircaloy-2, Zircaloy-4, M5 ${ }^{\mathrm{TM}}$, and ZIRLO ${ }^{\mathrm{TM}}$," Proceedings from the 2011 Water Reactor Fuel Performance Meeting, Chengdu, China, (2011).

[23] Applied Programming Technology, Inc. Symbolic Nuclear Analysis Package (SNAP) User's Manual, (2011). 